\title{
The analysis of capture fisheries performance in Lembeh Island, Bitung City, North Sulawesi
}

\author{
Analisis keragaan perikanan tangkap Pulau Lembeh, Kota Bitung, Sulawesi Utara
}

\author{
Muhammad Z. Arifin ${ }^{1 *}$, Emil Reppie ${ }^{2}$, Johnny Budiman ${ }^{2}$ \\ ${ }^{1}$ Program Studi Ilmu Perairan, Program Pascasarjana Universitas Sam Ratulangi. Jln. Kampus Unsrat Kleak, \\ Manado 95115, Sulawesi Utara, Indonesia. \\ ${ }^{2}$ Fakultas Perikanan dan Ilmu Kelautan, Universitas Sam Ratulangi. Jl. Kampus Unsrat Bahu, Manado 95115 , \\ Sulawesi Utara, Indonesia. \\ *E-mail:muzararifin@yahoo.com
}

\begin{abstract}
According to the statistics of 2014 Bitung City, fisheries production value of the city increased. This needs to be analyzed in order to establish whether the development provides economic benefit to the society and whether the fishing activities are efficient. The objectives of the study were to study the capture fisheries performance and its impact on the responsible fisheries management in Lembeh (as part of the Bitung City); to know the efficiency level of the fishing activities carried out by fishermen of Lembeh; and to analyze the economic benefit of the capture fisheries to the fishermen. The data were analyzed using descriptive methods. Results found that dominant fishing gears used by Lembeh fishermen were handlines (multihooks-handline, octopus handline, squid handline, and tuna handline), nets (beach seine and gill net), mini purse seine, and fish aggregating device (such as light boat). Those fishing gears were distributed in all villages of Lembeh. Efficient fishing activities are those with efficiency value of 1. From 111 fishermen respondents in Lembeh, 29 of them did efficient fishing operations. The range of investment needed for each fishing gear varied among different types. Mean fishermen's exchange rate of Lembeh island was 1.29, meaning that there was positive impact of fishing activities on the fulfillment of family's daily needs.
\end{abstract}

Keywords: fisheries performance; capture fisheries; fisheries management; Lembeh island; Bitung.

Abstrak: Menurut data statistik Kota Bitung dalam angka tahun 2014, nilai produksi perikanan Kota Bitung mengalami kenaikan. Kenaikan ini perlu di analisis apakah memberi manfaat secara ekonomi kepada masyarakat dan apakah penangkapannya sudah efisien. Tujuan penelitian ini adalah 1) menganalisis keragaan perikanan tangkap dan dampaknya pada pengelolaan perikanan yang bertanggung jawab di Pulau Lembeh (yang merupakan bagian dari Kota Bitung), 2) menetapkan tingkat efisiensi kegiatan perikanan tangkap yang telah dilakukan oleh nelayan di Pulau Lembeh, dan 3) menganalisa manfaat kegiatan perikanan tangkap secara ekonomi bagi para nelayan. Analisis data menggunakan metode deskriptif. Hasil penelitian menujukkan, bahwa alat tangkap yang dominan dioperasikan oleh nelayan Pulau Lembeh adalah jenis handline (pancing noru, pancing, pancing gurita, pancing cumi, pancing tuna), soma (beach seine dan gillnet), mini purse seine (pajeko), dan pengumpul ikan (perahu lampu). Alat tangkap tersebut tersebar di seluruh kelurahan di Pulau Lembeh. Kegiatan penangkapan yang efisien adalah kegiatan penangkapan dengan nilai efisiensi 1. Dari 111 responden nelayan pulau Lembeh, 29 di antaranya melakukan operasi penangkapan yang efisien. Kebutuhan modal usaha masing-masing alat tangkap berbeda antara satu dan lainnya. Rata-rata Nilai Tukar Nelayan (NTN) di pulau tersebut adalah 1,29 di mana menunjukkan adanya dampak positif kegiatan penangkapan ikan dalam pemenuhan kebutuhan sehari hari.

Kata-kata kunci: keragaan perikanan; perikanan tangkap; pengelolaan perikanan; pulau Lembeh; Bitung.

\section{PENDAHULUAN}

Pada tahun 2012, produksi perikanan Kota Bitung mengalami kenaikan 8,33\%, dibanding tahun sebelumnya, yaitu dari $147.069,8$ ton menjadi $159.319,4$ ton. Seiring dengan hal itu, tejadi kenaikan nilai produksi sebesar $0,02 \%$, yaitu dari
Rp 1.691,58 milyar menjadi Rp 1.692,02 milyar (Bitung Dalam Angka, 2013).

Produksi perikanan laut tahun 2013 mengalami penurunan sebesar $16,35 \%$, yakni dari $159.319,4$ ton menjadi $133.277,6$ ton. Penurunan tersebut tidak berpengaruh pada nilai produksi perikanan laut pada tahun 2013, yang mengalami peningkatan yang signifikan, yaitu sebesar $66,68 \%$, 


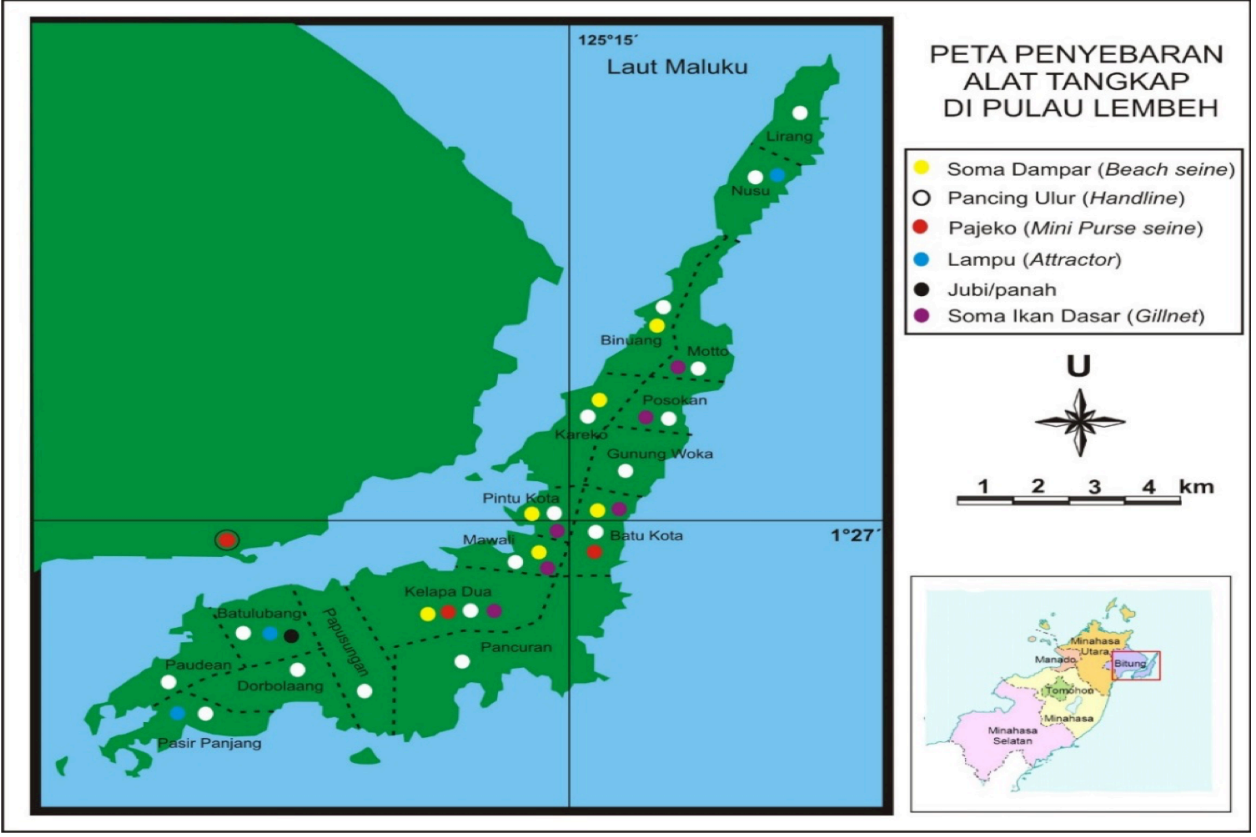

Gambar 1. Peta sebaran alat tangkap ikan di Pulau Lembeh, Bitung, Sulawesi Utara

yakni dari Rp 1.692,02 milyar (pada tahun 2012) menjadi 2.820,27 milyar tahun 2013 (Bitung Dalam Angka, 2014).

Berdasarkan hal diatas, maka perlu ditelaah lebih jauh apakah kenaikan nilai produksi hasil tangkapan tersebut, secara ekonomi, memberi manfaat bagi para pelaku usaha perikanan tangkap, dan juga apakah masih dapat dikatakan efisien operasi penangkapan yang dilakukan oleh para pelaku usaha penangkapan ikan. Tujuan penelitian ini, yaitu 1) melakukan analisis tentang keragaan perikanan tangkap dan dampaknya pada pengelolaan perikanan yang bertanggung jawab di Pulau Lembeh, 2) menetapkan tingkat efisiensi kegiatan perikanan tangkap yang telah dilakukan oleh nelayan Pulau Lembeh, dan 3) menganalisis manfaat kegiatan perikanan tangkap secara ekonomi bagi para nelayan.

\section{MATERIAL DAN METODA}

Penelitian ini dilaksanakan di beberapa kelurahan di Pulau Lembeh, Kota Bitung, Provinsi Sulawesi Utara, pada bulan Juni 2015 sampai dengan Juni 2016. Nelayan, yang merupakan responden, berasal dari 8 (delapan) kelurahan. Jumlah total nelayan yang dijadikan sebagai responden sebanyak 111 Orang.

Bahan dan alat yang digunakan dalam penelitian, yaitu software DEA (Max DEA 6.3), CorelDRAW X4, meteran dan alat tulis, laptop,

daftar panduan pertanyaan (kuisioner), perahu, kamera

Data primer yang dikumpulkan dari pelaku utama adalah: data modal usaha yang dikeluarkan per trip penangkapan, data pendapatan dari penjualan hasil tangkapan, data spesifikasi armada penangkap ikan, data spesifikasi alat tangkap ikan, dan data nilai jual hasil tangkapan. Data sekunder yang dikumpulkan dari data instansi terkait, yaitu: data informasi keadaan sosial dan kependudukan, data mengenai jumlah nelayan, dan data armada penangkapan ikan.

Analisis data yang dilakukan pada penelitian ini menggunakan metode deskriptif dengan menggunakan Data Envelopment Analysis (DEA) untuk mengetahui efektifitas dan efisiensi kegiatan penangkapan yang telah dilakukan. Software DEA yang digunakan adalah Software Max DEA 6.3. Penghitungan Efisiensi menggunakan DEA menggunakan acuan sebagai berikut:

DMU: nelayan yang ada di kelurahan di Pulau Lembeh. DMU ditulis dalam notasi kode yaitu:

$\begin{array}{ll}\text { PSP } & \text { : Nelayan di Pasirpanjang } \\ \text { PDN } & \text { : Nelayan di Paudean } \\ \text { BLT } & \text { : Nelayan di Batulubang } \\ \text { BLU } & \text { : Nelayan di Batulubang } \\ \text { KLD } & \text { : Nelayan di Kelapa Dua } \\ \text { KLN } & \text { : Nelayan di Kelapa Dua } \\ \text { KLS } & \text { : Nelayan di Kelapa Dua } \\ \text { PKK } & \text { : Nelayan di Pintukota } \\ \text { BTK } & \text { : Nelayan di Batukota } \\ \text { KRK } & \text { : Nelayan di Kareko } \\ \text { MTO } & \text { : Nelayan di Motto }\end{array}$


Tabel 1 Jenis Armada Penangkapan dan Alat tangkap di Pulau Lembeh, Kota Bitung, Provinsi Sulawesi Utara

\begin{tabular}{|c|c|c|c|c|c|c|c|}
\hline \multirow[b]{2}{*}{ No } & \multirow{2}{*}{$\begin{array}{l}\text { Jenis Alat } \\
\text { Tangkap }\end{array}$} & \multirow{2}{*}{$\begin{array}{c}\text { Armada } \\
\text { Penangkapan }\end{array}$} & \multicolumn{5}{|c|}{ Keterangan } \\
\hline & & & Dimensi (cm) & $\operatorname{Mesin}(\mathrm{PK})$ & $\begin{array}{l}\text { Trip } \\
\text { (Hari) }\end{array}$ & $\begin{array}{c}\text { ABK } \\
\text { (orang) }\end{array}$ & Alat Navigasi \\
\hline \multicolumn{2}{|c|}{$\begin{array}{l}1 \text { Handline } \\
\text { Pancing Tuna }\end{array}$} & Kapal Tuna & $1200 \times 230 \times 150$ & Mesin $40 \mathrm{PK}$ & 14 & $5-10$ & $\begin{array}{l}\text { Kompas, } \\
\text { GPS, Radio }\end{array}$ \\
\hline \multicolumn{2}{|c|}{ Pancing Noru } & Perahu Katinting & $750 \times 80 \times 80$ & Katinting $13 \mathrm{PK}$ & 1 & $1-2$ & No \\
\hline \multicolumn{2}{|r|}{ Pancing Cumi } & Perahu Katinting & $700 \times 80 \times 120$ & Katinting $13 \mathrm{PK}$ & 1 & $1-2$ & No \\
\hline \multicolumn{2}{|c|}{ Pancing Gurita } & Perahu Katinting & $500 \times 80 \times 100$ & Katinting 13 PK & 1 & $1-2$ & No \\
\hline \multicolumn{2}{|c|}{2 Lampu } & Perahu Katinting & $750 \times 80 \times 80$ & Katinting $13 \mathrm{PK}$ & 1 & $1-2$ & No \\
\hline \multicolumn{2}{|c|}{$\begin{array}{l}3 \text { Soma } \\
\text { Pajeko (Mini }\end{array}$} & Perahu Katinting & $700 \times 80 \times 120$ & Katinting $13 \mathrm{PK}$ & 1 & $1-10$ & No \\
\hline \multicolumn{2}{|c|}{4 Purse seine) } & Pajeko & $1750 \times 370 \times 370$ & Mesin $40 \mathrm{PK}$ & 1 & $5-20$ & No \\
\hline
\end{tabular}

\section{Parameter Input}

X1: Besar Biaya BBM Rata-rata pertrip (Rp)

$\mathrm{X} 2$ : Besar Kebutuhan lainnya selain BBM pertrip (Rp)

X3: Jumlah ABK (Anak Buah Kapal) (Orang)

$\mathrm{X} 4$ : Lama waktu yang diperlukan pertrip (Hari)

\section{Parameter Output}

Y : Nilai Total Hasil Tangkapan rata rata pertrip (Rp)

Untuk mengetahui apakah kegiatan penangkapan ikan yang telah dilakukan telah memberikan dampak positif secara ekonomi, digunakan analisis menggunakan konsep nilai tukar nelayan (NTN) dan analisis Usaha kegiatan Penangkapan Ikan. Menurut Basuki dkk. (2001) dalam Gede (2006), NTN adalah rasio total pendapatan terhadap total pengeluaran rumah tangga nelayan selama periode waktu tertentu. Dalam hal ini, pendapatan yang dimaksud adalah pendapatan kotor atau dapat disebut sebagai penerimaan rumah tangga nelayan. NTN dapat dirumuskan sebagai berikut :

$$
\begin{aligned}
& \mathrm{NTN}=\mathrm{Yt} / \mathrm{Et} \\
& \mathrm{Yt}=\mathrm{YFt}+\mathrm{YNFt} \\
& \mathrm{Et}=\mathrm{EFt}+\mathrm{EKt}
\end{aligned}
$$

Di mana :

YFt : Total penerimaan nelayan dari usaha perikanan (Rp)

YNFt : Total penerimaan nelayan dari non perikanan $(\mathrm{Rp})$

EFt : Totalpengeluaran nelayan untuk usaha perikanan $(\mathrm{Rp})$

EKt : Total pengeluaran nelayan untuk konsumsi keluarga nelayan $(\mathrm{Rp})$

$\mathrm{T} \quad$ : periode waktu (bulan, tahun, dll)

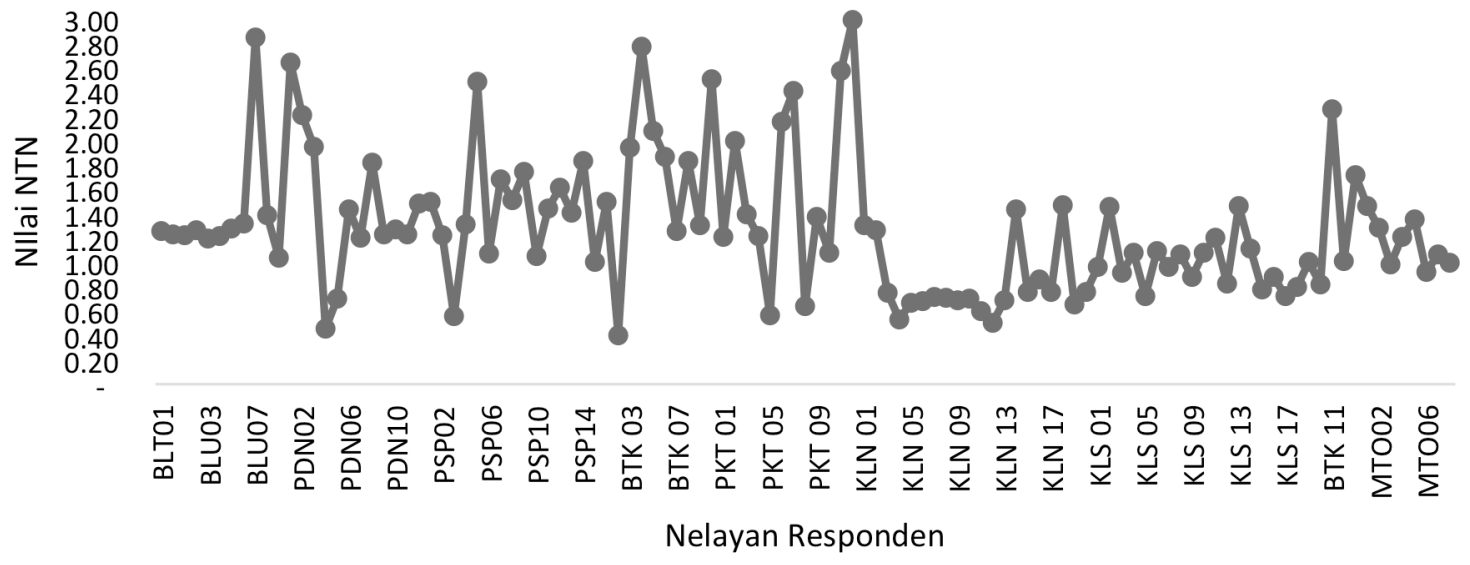

Gambar 2. Nilai Tukar Nelayan (NTN) di Pulau Lembeh, Kota Bitung, Provinsi Sulawesi Utara 
Arifin et al.: The analysis of capture fisheries performance in Lembeh Island, ...

Tabel 2. Modal usaha penangkapan ikan nelayan di Pulau Lembeh, Kota Bitung, Provinsi Sulawesi Utara

\begin{tabular}{rlcl}
\hline No & \multicolumn{1}{c}{ Jenis Alat Tangkap } & Nilai Investasi (jt) & \multicolumn{1}{c}{ Keterangan } \\
\hline 1 & Handline & & Investasi pada Kapal/Perahu, \\
& Pancing Tuna & $150-200$ & Alat Tangkap Ikan, Alat \\
& Pancing Noru & $12-20$ & \\
& Pancing Cumi & $7-8$ & \\
& Pancing Mesin. \\
& Pancing Gurita & $3-20$ & \\
2 & Lampu & $9-12$ & \\
3 & Soma & $10-30$ & \\
4 & Pajeko (Mini Purse seine) & $90-250$ & \\
\hline
\end{tabular}

Tabel 3. Biaya per trip penangkapan ikan nelayan di Pulau Lembeh, Kota Botung, Provinsi Sulawesi Utara

\begin{tabular}{|c|c|c|c|}
\hline No & Jenis Alat Tangkap & Biaya pertrip (Rp.000,-) & Keterangan \\
\hline \multirow[t]{5}{*}{1} & Handline & & Biaya Untuk Konsumsi, \\
\hline & Pancing Tuna & $10,000-30,000$ & \\
\hline & Pancing Noru & $150-300$ & \\
\hline & Pancing Cumi & $90-120$ & \\
\hline & Pancing Gurita & $100-350$ & \\
\hline 2 & Lampu & $150-300$ & \\
\hline 3 & Soma & $200-300$ & \\
\hline 4 & Pajeko (Mini Purse seine) & $1,000-2,700$ & \\
\hline
\end{tabular}

Nilai NTN dijelaskan sebagai berikut :

NTN > 100 atau 1, berarti nelayan mengalami peningkatan daya beli karena kenaikan harga produksi lebih besar dari kenaikan harga input produksi dan konsumsi rumah tangganya.

$\mathrm{NTN}=100$ atau 1 , berarti petani mengalami impas (break even point). Persentase kenaikan/ penurunan harga produksinya sama dengan persentase kenaikan/penurunan harga input produksi dan barang konsumsi rumah tangganya.

NTN $<100$ atau 1, berarti nelayan mengalami defisit/penurunan daya belinya karena kenaikan harga produksi relatif lebih kecil dibandingkan dengan kenaikan harga input produksi dan barang konsumsi rumah tangganya.

\section{HASIL DAN PEMBAHASAN}

Nelayan merupakan jenis mata pencaharian dominan di Pulau Lembeh di mana sebanyak 39,5\% berada di Kecamatan Lembeh Selatan dan 52,15\% berada di Kec. Lembeh Utara. Alat tangkap ikan yang digunakan adalah jenis handline (noru, tuna, cumi, dan gurita), soma (beach seine dan gillnet), pajeko (mini purse seine), panah/jubi, dan perahu lampu. Peta sebaran alat tangkap tersebut dapat dilihat pada Gambar 1.

Jenis armada penangkapan yang digunakan berbeda-beda; sebagai contoh, handline tuna akan berbeda dengan handline noru, dan lainnya (Tabel 1). Perbedaan jenis armada dan alat tangkap mempengaruhi besaran modal usaha dan biaya per trip penangkapan (Tabel 2 dan Tabel 3).

Berdasarkan analisa data, ditemukan 29 orang nelayan/responden yang kegiatan penangkapannya bernilai efisien atau bernilai 1 (satu) (Tabel 24. Nilai Tukar Nelayan (NTN) di Pulau Lembeh berada antara 0.40 dan 2.99, dengan nilai rata-rata adalah 1.28. Nilai NTN pada masingmasing nelayan/responden tiap kelurahan disajikan pada Gambar 2.

Nilai rata NTN Pulau Lembeh secara umum lebih tinggi dari NTN rata-rata nasional tahun 2015, yaitu 1.05. Nilai rata-rata NTN nelayan Pulau Lembeh yang cukup baik ini mengindikasikan, bahwa kegiatan penangkapan yang dilakukan selama ini cukup memberikan dampak positif terhadap pemenuhan kebutuhan sehari-hari dan untuk membiayai kebutuhan lainnya. Nilai rata-rata NTN yang lebih besar dari 1 mengindikasikan, bahwa ada dana surplus atau dana sisa dari kegiatan 
Tabel 4. Nelayan di Pulau Lembeh yang operasi penangkapannya bernilai efisien

\begin{tabular}{clcclc}
\hline NO & DMU & Score & NO & DMU & Score \\
\hline 1 & PSP10 & 1 & 16 & KLN 02 & 1 \\
2 & PSP14 & 1 & 17 & KLN 14 & 1 \\
3 & PDN03 & 1 & 18 & KLN 18 & 1 \\
4 & PDN06 & 1 & 19 & KLS 02 & 1 \\
5 & PDN10 & 1 & 20 & KLS 13 & 1 \\
6 & BLT01 & 1 & 21 & KLS 14 & 1 \\
7 & BLT02 & 1 & 22 & PKK 08 & 1 \\
8 & BLU02 & 1 & 23 & PKK 11 & 1 \\
9 & BLU04 & 1 & 24 & BTK 02 & 1 \\
10 & BLU06 & 1 & 25 & BTK 08 & 1 \\
11 & BLU08 & 1 & 26 & BTK 10 & 1 \\
12 & BLU09 & 1 & 27 & KRK 02 & 1 \\
13 & KLD 01 & 1 & 28 & MTO02 & 1 \\
14 & KLD 02 & 1 & 29 & MTO05 & 1 \\
15 & KLN 01 & 1 & & & \\
\hline
\end{tabular}

konsumsi dan pemenuhan lebutuhan lainnya. Dana surplus sebesar $0.28 \%$ merupakan dana yang tidak habis dalam pemanfaatan. Dana itu bisa dimanfaatkan lebih lanjut untuk ditabung, untuk pengembangan usaha, baik usaha perikanan maupun usaha lainnya atau bisa pula untuk ditabung.

\section{KESIMPULAN}

Berdasarkan hasil analisis dan pembahasan dapat disimpulkan, bahwa :

1. Jenis alat tangkap nelayan Pulau Lembeh, yang dominan dioperasikan, adalah jenis handline (pancing noru, pancing, pancing gurita, pancing tuna), beach seine net dan gillnet (soma), mini purse seine (pajeko), panah/jubi dan pengumpul ikan (perahu lampu). Alat tangkap tersebut tersebar di seluruh kelurahan di Pulau Lembeh.

2. Dari 111 responden nelayan Pulau Lembeh, 29 di antaranya melakukan operasi penangkapan yang efisien.

3. Kebutuhan modal usaha masing-masing alat tangkap, yaitu: handline noru dan gurita: $\mathrm{Rp}$ 3.000.000,- sampai dengan (s/d) Rp 20.000.000,-; handline cumi: Rp 7.000.000,- s/d $\mathrm{Rp} \quad 8.000 .000,-;$ handline tuna: $\mathrm{Rp}$ 150.000.000,- s/d Rp 200.000.000,-; perahu lampu: Rp 9.000.000,- s/d Rp 12.000.000,-; soma (beach seine net) Rp 10.000.000,- s/d Rp 30.000.000,-; dan pajeko (mini purse seine): Rp $90.000 .000,-$ s/d Rp 250.000.000,-.
4. Rata-rata Nilai Tukar Nelayan (NTN) Pulau Lembeh adalah 1,28; menunjukkan adanya manfaat secara ekonomi dari kegiatan penangkapan ikan dalam pemenuhan kebutuhan sehari hari.

Ucapan Terima kasih: Penulis ucapkan terima kasih kepada pihak-pihak yang telah membantu dalam penyelesaian penelitian ini, yang tidak bisa penulis sebutkan satu persatu; namun, kiranya hal itu tidak mengurangi hormat dan terima kasih penulis kepada pihak-pihak tersebut.

\section{REFERENSI}

DITJEN PERIKANAN, DEPARTEMEN PERTANIAN (1979). Buku Pedoman Pengenalan Sumberdaya Perikanan Laut Bagian I (Jenis-Jenis Ikan Ekonomis Penting). Jakarta: Departemen Pertanian.

DJPT (2011) Peta Keragaan Perikanan Tangkap di WPP RI Cetakan III. Jakarta: DJPT KKP.

DKP SULUT (2010) Buku Statistik Perikanan Tangkap 2010. Manado: Dinas Kelautan dan Perikanan Sulut.

FAUZI, A. (2005) Kebijakan Perikanan dan Kelautan, Isu, Sintesis dan Gagasan. Jakarta: PT Gramedia Pustaka Utama.

FAUZI, A. and SUZY, A. (2005) Permodelan Sumberdaya Perikanan dan Kelautan Untuk Analisa Kebijakan. Jakarta: Penerbit PT Gramedia Pustaka Utama.

USTRIYANA, I N.G. (2005) Model dan Pengukuran Nilai Tukar Nelayan (Kasus Kabupaten Karangasem). Bali: Fakultas Pertanian Universitas Udayana.

KHUMAIROH, ISMAIL, YULIANTO. T. (2013) Analisis Tingkat Kesejahteraan Rumah Tangga Nelayan Purse Seine di PPI Bulu Kabupaten Tuban Jawa Timur. Journal of Fisheries Resources Utilization Management and Technology, 2(3): 182-191

NIKIJULUW, V.PH. (2008) Blue Water Crime (Cetakan Pertama). Jakarta: PT Pustaka Cidesindo.

PLANNING BUREAU OF MMAF. (2009) Indonesian Fisheries Book 2009. Jakarta: Ministry Marine Affairs and Fisheries and JICA.

PUSAT DATA STATISTIK DAN INFORMASI. (2013) Analisa dan Data Pokok Kelautan dan Perikanan Menurut Provinsi Tahun 2012. Jakarta: Sekretariat Jenderal Kementerian Kelautan dan Perikanan. 
Arifin et al.: The analysis of capture fisheries performance in Lembeh Island, ...

SANDJAJA, B. and HERIYANTO, A. (2015)

Received: 15 June 2017

Panduan Penelitian (Edisi Revisi). Jakarta: Accepted: 10 August 2017

Prestasi Pustaka Publisher.

WIDODO, J. and SUADI. (2008) Pengelolaan

Sumberdaya Perikanan Laut. Yogyakarta:

Gadjah Mada University Press. 